\title{
Exploring the Invisible Pain of Workplace Ostracism: Its Outcomes \& Coping Mechanism
}

\author{
Himani Oberai ${ }^{\mathbf{a}}$ \\ ${ }^{\mathrm{a} A s s i s t a n t ~ P r o f e s s o r, ~ I n s t i t u t e ~ o f ~ B u s i n e s s ~ M a n a g e m e n t, ~ G L A ~ U n i v e r s i t y, ~ M a t h u r a, ~ I n d i a . ~}$ \\ E-mail: himani.oberai@gla.ac.in
}

Article History: Received: 11 January 2021; Accepted: 27 February 2021; Published online: 5 April 2021

\begin{abstract}
Workplace ostracism is a form of silent mistreatment where an individual experiences deliberate denied social interaction with others. It is believed to be a universal phenomenon which silently injures the human heart. Ostracism is believed to be very destructive as the ostracized person finds it difficult to prove that he is being ostracized due to its covert nature. It is a proven fact that the nature of mistreatment under ostracism can be silent but its outcomes in the form of decreased job engagement, diminished work performance, increased intention to quit, etc. are very vocal. The relationship between workplace ostracism and its negative consequences is explained in the light of Conservation of Resources theory. According to conservation of resources theory, every individual is attached to various kinds of resources which they perceive as worthy. The theory claimed that when an individual encounters resource loss or is threatened of potential loss, such experiences disturbs his psychological well-being. This study also describes the coping mechanism which an individual can adopt in order to manage the negative aspects of workplace ostracism. The organizational administrators need to focus on this silent form of harassment, which is making the organization weak on a broader scope. Thus, a serious need of encouraging healthy communication, cooperation and coordination is required in every organization in order to avoid counter-productive work behaviors.
\end{abstract}

Keywords: Workplace Ostracism, Conservation of Resources Theory, Counter-productive Work Behaviors, Coping Mechanism.

\section{Introduction}

Workplace Ostracism is a universal phenomenon which causes social pain to an individual (Ferris et al., 2008). Blackhart et al., (2009) define the term ostracism as, "the experience of being deliberately denied social contact by others from whom one might expect such contact". Thus, it is an individual's perception of being excluded or ignored by other people around him (Ferris et al., 2008). MacDonald and Leary (2005) reported workplace ostracism as one of the most hurtful experience in a human's life. The literature also posits that an ostracized human brain feels the similar level of pain as it feels under physical injuries because the same brain structures are connected.

Workplace ostracism can take up different forms (Duffy et al., 2002). An individual can feel ostracized when people around him simply ignores his greetings, people ignoring at lunch breaks, offering a cold shoulder, not inviting for social gathering in office, etc. Williams (2007) clearly indicated in his study that an ostracized individual when ignored by his colleagues or seniors at work starts believing himself as an outsider to the organization which ultimately threatens his sense of belongingness. This is in accordance to social identity perspective which posits that an individual's intentions and behaviors are guided by the perception and identification of themselves with others (Tajfel, 1978).

According to Williams (2007), ostracism causes social pain to an individual and is potential of threatening four basic needs of human. First, it threatens an individual's self-esteem, which makes him feel as if he has done something wrong because of which people around are ignoring him. Next in line, their need of belongingness is in danger as an ostracized employee feels as if he is eliminated from the group to which he belongs. Third, they looses their sense of control because the trauma which they encounter due to non-responsiveness of others makes them loss their control certain times. Fourth, when an individual is ostracized his sense of meaningful existence is impacted negatively which traumatize the individual.

\section{Objective of Study}

The main objective of the present study is to explore and investigate how ostracism is impacting employees and their behavior at work. In the past, ostracism was majorly studied under different disciplines like deviant workplace, workplace bullying, etc. (Duffy et al., 2002). Thus, this study is unique as it highlights the varied consequences of workplace ostracism and its coping mechanism. A conceptual model is being proposed based on the extensive literature study.

\section{Theoretical Background}




\subsection{Conservation of Resources Theory}

The present study takes the help of conservation of resources (Hobfoll, 1989) theory in order to explain the mechanism between workplace ostracism and its negative consequences. According to conservation of resources theory, every individual is attached to various kinds of resources which they perceive as worthy. The resources can be in the form of physical objects, social ties, etc. (Hobfoll, 1989, 2002). The theory posited that when an individual encounters resource loss or is threatened of potential loss, such experiences disturbs his psychological well-being. Further, that individual is motivated to exhibit such actions which help him either in conserving the remaining resources or generating more resources for future use.

Additionally, Hobfoll (2001) under conservation of resources theory posited that every individual when face resource loss due to some adverse working situation bounce back in order to acquire, retain or uphold his valuable resources. Thus, when an employee is ostracized at work, this drains his positive resources in terms of support from people around him. Such adverse situation at work enhances his emotional exhaustion and disturbs his mental well-being; which further motivates him to exhibit such behaviors which are favourable for conserving remaining resources (Wu et al., 2012).

In addition to the above literature, Leung et al., (2011) also proposed that adverse event in the form of ostracism at work is enough to drain valuable resources from individual which keeps him moving at work. Such circumstances activate or energize an employee's protection mechanism in order to safeguard the remaining resources.

\subsection{Workplace Ostracism and Counter-Productive Work Behaviors}

In a survey by Fox and Stallworth (2005), over 66\% of the employees claimed that they experienced "silent harassment at work" in the form of ostracism. In addition to this a study by Hitlan et al., (2006) revealed that out of 5000 workers 650 reported that they had been excluded at work one or the other time. Workplace ostracism has the potential to leave devastating impact on the employee's well-being. Thus, it is imperative to understand the impact of workplace ostracism on work behaviors.

\subsubsection{Workplace Ostracism \& Work Stress}

Chung (2018) in a study posited that the past literature is missing on the relationship between ostracism at work and an employee's perception of stress. In line with this, Ferris et al., (2008) stated that workplace ostracism is an unpleasant experience which has severe impact on employee's mental well-being. The past literature clearly states that ostracism aggravates frustration, anxiety, dissatisfaction and exhaustion (Wu et al., 2012; Colligan \& Higgins, 2006). Further, it leads to feeling of sadness, sorrow, stress, etc. (Williams, 2001).

According to O'Reilly \& Robinson (2009), employees are ostracized when they are ignored or excluded at social events by colleagues or seniors. Such adverse event at work reduces the social communication among the members of organization which ultimately is seen as organizational stressor (Heaphy \& Dutton, 2008).

\subsubsection{Workplace Ostracism \& Turnover Intention}

Price (2001) defined turnover intention as an individual's willingness to permanently depart from the organization. Bigliardi et al., (2005) posited that an individual's intention to quit is believed to be the direct predictor of their actual behavior to quit. The extant literature suggests that an employee who feels excluded or ignored by fellow colleagues very often develops the intention to quit his present workplace (Kurzban \& Leary, 2001).

In the light of COR theory it is suggested that ostracized employees engages themselves in such behaviors where they try to retain or maximize their lost resources (Hobfoll, 2011). In continuation to this it is observed that ostracized employees in order to avoid the source of ostracism develop an intention to leave their workplace where they perceive exclusion and ignorance (Renn et al., 2013). This is supposed to be an adaptive reaction to the adverse event which an employee encounters in the form of ostracism. In order to minimize the painful impact of ostracism and retain their remaining social and psychological resources they develop an intention to quit the organization. This is in line with conservation of resources theory which elaborates the mechanism of retaining and maximizing one's personal resources (Hobfoll et al., 2018).

\subsubsection{Workplace Ostracism \& Task Performance}

An employee's social interactions with his fellow colleagues or seniors are broken when he perceives ostracism at work (Ferris et al., 2008). The extant literature demonstrates workplace ostracism to be more severe in comparison to direct adverse work situations like bullying, verbal abuse, physical harassment, etc. (Zadro et al., 2004). Twenge et al., (2007) claimed that workplace ostracism shares a negative relationship with an employee's pro-social behaviors at work. Not just this, it is also reported that workplace ostracism deteriorates an individual's mental performance and also impedes tendency of aggression among them (Warburton et al., 2006; Baumeister et al., 2002). 
When an employee encounters adverse work event in the form of ostracism, it causes energy depletion within them. This is in line with conservation of resources theory (Hobfoll, 2001). The ostracized employees deviate from their work goal which hampers their ability to accomplish their job requirement (Abbas et al., 2014). In fact it is observed that when an employee gets full support from seniors and colleagues, his performance increases manifold. Wu et al., (2012) also postulated in his study that when an employee is lend a cold shoulder by his colleagues and peers, his energy level decreases which further demotivates him to give good performance at work.

When an employee perceives that he is being excluded by his social work group, he cannot look forward to them for any help for accomplishing his job assignments. Sometime this communication gap which is created due to ostracism deteriorates the work performance (Seibert et al., 2001). When employees are ostracized at workplace they have the tendency to develop negative emotions like worrying, upsetting, etc. which is believed to diminish his performance at work (McCarthy et al., 2016).

In the above backdrop, it is seen that when an employee is excluded from social gatherings, lunch breaks, conversations, social activities, etc. he starts perceiving himself as he is not required in the organization. Thus, they indulge themselves in minimizing their efforts towards the organization. Further, if it continues the ostracized employee starts considering him as a low-value employee. This marks the beginning where he feels as if his personal ego or self respect is threatened at work, and reduce his self- confidence manifold. Due to decreased levels of self confidence, the ostracized employees are not able to give good performance at work (Sommer \& Baumeister, 2002), this is in line with conservation of resources theory (Hobfoll, 2011).

\subsubsection{Workplace Ostracism \& Job Engagement}

Engaged employees are characterized by three terms i.e. Vigor (hardworking nature of employee), dedication (level of involvement with work) and absorption (engrossed with work) (Shkoler \& Kimura, 2020). Park \& Ono (2017) reported that employees with high level of engagement possess high level of energy and enthusiasm to accomplish their task. Researchers study job engagement construct because they consider it to be a very important work behavior which defines the success of an employee and overall organization in long term (Huertas-Valdivia et al., 2018).

Bellou (2016) defined ostracism as "to be voted out". It is only in recent years that ostracism has received academic attention from researchers (Williams, 2007). When an employee is ostracized it is posited to have severe impact on his attitude formation and final behavior (Bellou, 2016). It is believed that when an employee is ostracized at work, it impacts their psychological well-being (Park \& Ono, 2017) which ultimately impacts their engagement towards the work. According to conservation of resources theory workplace ostracism deteriorates an individual's personal resources which keep them motivated at work (Hobfoll, 2011). Among employees the engagement level decreases when they perceive severe loss of personal resources after facing adverse situation at work in the form of ostracism.

Workplace ostracism is posited to decrease an individual's energy and enthusiasm towards his work (Kaya, 2017). It is also reported that when an employee perceives that he is being excluded in social interactions by others this negatively impacts their cognitive and affective levels of engagement. Thus, it is observed in the extant literature that workplace ostracism shares a strong and negative relationship with job engagement.

\subsection{Workplace Ostracism: Coping Mechanism}

According to Williams (2001), ostracism is supposed to be an interpersonal stressor which aggravates psychological distress among the ostracized individuals. The above section elaborates on how workplace ostracism leads to undesirable or counter-productive work behaviors in the form of decreased work performance, increased intention to quit job, decreased job performance, etc. Thus, it is believed that every individual who face such adverse work situation experiences many negative impacts.

Moreover, it has become critical to develop an understanding about how an individual can cope with such adverse work place events in order to mitigate the impact of its negative outcomes (Williams, 2007). The below section discusses the strategies which an employee can use in order to manage the detrimental effects of workplace ostracism.

First, an ostracized employee needs to control his aggression and anger for the people who ignore them at social gatherings. When an employee is ostracized at work, many times it makes him frustrated and aggressive (Warburton et al., 2006). And this aggression many a times makes the ostracized individual violent towards others. Thus, he needs to control his anger so that he does not indulge in to any kind of misconduct at work.

Second, ingratiation is considered to be one of the most effective coping strategies when faced with the challenge of workplace ostracism (Williams \& Zadro, 2005). Liden and Mitchell (1988) defined ingratiation as, "an attempt by individuals to increase their attractiveness in the eyes of others". Thus, it is believed that when an individual starts perceiving ostracism, in order to become the part of social group he should put some efforts in order to impress others. Although, the research suggests that the success of such behavioral strategies tends to 
vary from individual to individual. Also the person exhibiting ingratiation needs to be an expert in influencing others towards him.

Third, possession of political skill is also considered as an important strategy for managing workplace ostracism. Ferris et al., (2012) defined political skill as an, "individual's ability to effectively understand others at work and to use such knowledge to influence others to act in ways that enhance one's personal or organizational objectives". Thus, if an individual possess political skill, that means he is a person full of tact who knows what to speak at what time and with what level. This will make him get included in the group which he is longing for.

Fourth, self-efficacy represents one such personal resource which has the potential to diminish the negative impact of workplace ostracism. Thus, high level of self-efficacy among an employee may save him from the deleterious impact of workplace ostracism. In the words of Schmitz and Ganesan (2014), self- efficacy is that distinct and important personal resource within an individual which enables him to survive and find solutions even under adverse working situations. Moreover, individuals with high levels of self-efficacy are able to understand the origin of resource-draining work events and try to minimize the negative impact of it (Abbas et al., 2014).

Fifth, maintain professionalism at workplace will help you in avoiding the negative thoughts of ostracism. It is suggested that you should not give enough opportunities to others to ostracize you. Try your best to ignore such disregard from the peers or seniors. Just stay focused on your work and stays happy with small social group. Sixth, if possible discuss with the human resource manager about your perception. In some situations counseling or mentoring can also help the employees to avoid unpredictable problems of this phenomenon.

\section{Proposed Model}

Thus, based on the above literature this study proposes a model which discusses the impact of workplace ostracism and its coping strategies. The extant literature suggests that almost every individual face challenges at work in the form of workplace ostracism. The severity of this social exclusion varies from person to person. The model provides deep insight on how workplace ostracism leads to counter productive work behaviors. Further, the model also discusses the coping mechanism for the same. Figure 4.1 represents the proposed model based on comprehensive literature review.

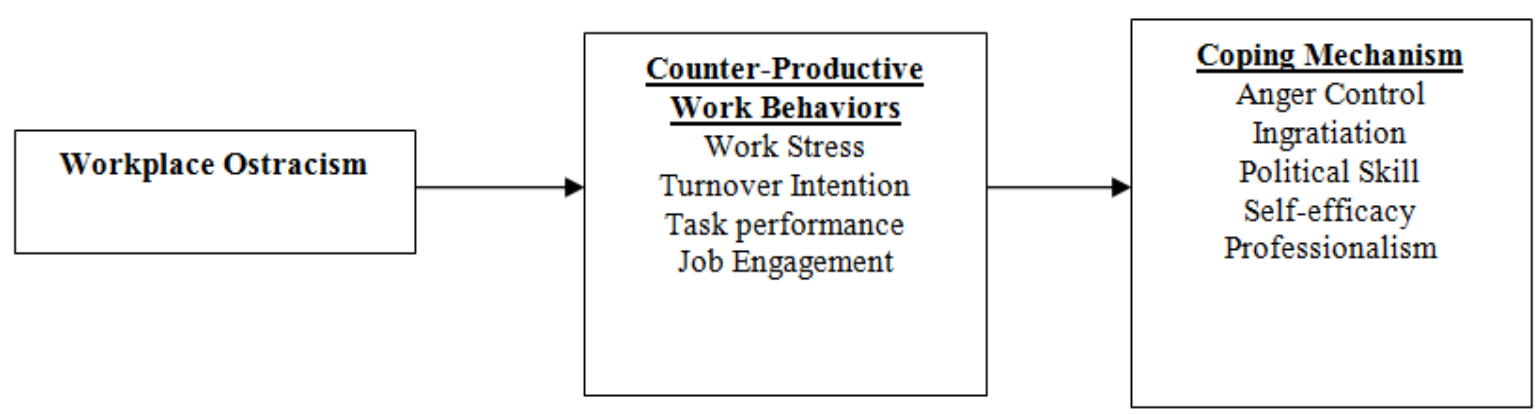

Figure 4.1. Proposed Model

\section{Future Research Scope}

In view of further validating the model proposed in present study, an empirical study can be conducted in near future. The present study does not present any insights on cross-cultural dimensions. Thus, in future study workplace ostracism can be used to understand the individual's intention across different countries. Further, to make the present study more vulnerable, various demographic variables can be explored in this context.

\section{Conclusion}

Workplace ostracism is a silent or passive form of employee harassment where the actions are covert but leaves a deep negative impact on an individual's psychological well-being. This study demonstrates how ostracism at work can hit the organization's bottom line. The present study contributed to the academic literature by providing deep insights about the counter-productive work behaviors of an individual when he is ostracized at work. Also this study suggests some of the coping mechanisms which individuals can acquire when they are being ostracized at work. Moreover, this study highlights that the poor interpersonal behavior not only impacts the well-being of ostracized employees, but it leaves a negative impact on the overall organizational well-being.

Therefore, it is the need of the hour that organizational administrators need to focus on this silent type of harassment, which is making the organization weak on a broader scope. Thus, a serious need of encouraging healthy communication, cooperation and coordination is required. Every employee in the organization should be given opportunities to satisfy their social needs and in fact every member should try their best to make the social ties more strong in order to cope with ostracism at work. 


\section{References}

1. Abbas, M., Raja, U., Darr, W., \& Bouckenooghe, D. (2014). Combined effects of perceived politics and psychological capital on job satisfaction, turnover intentions, and performance. Journal of Management, 40(7), 1813-1830.

2. Baumeister, R.F., Twenge, J.M., \& Nuss, C.K. (2002). Effects of social exclusion on cognitive processes: anticipated aloneness reduces intelligent thought. Journal of personality and social psychology, 83(4), 817.

3. Bellou, V. (2016). The relationship between workplace ostracism and information exchange. Management Decision, 54(3), 700-713.

4. Bigliardi, B., Petroni, A., \& Dormio, A.I. (2005). Organizational socialization, career aspirations and turnover intentions among design engineers. Leadership \& organization development journal.

5. Blackhart, G.C., Nelson, B.C., Knowles, M.L., \& Baumeister, R.F. (2009). Rejection elicits emotional reactions but neither causes immediate distress nor lowers self-esteem: A meta-analytic review of 192 studies on social exclusion. Personality and Social Psychology Review, 13(4), 269-309.

6. Chung, Y.W. (2018). Workplace ostracism and workplace behaviors: A moderated mediation model of perceived stress and psychological empowerment. Anxiety, Stress, \& Coping, 31(3), 304-317.

7. Colligan, T.W., \& Higgins, E.M. (2006). Workplace stress: Etiology and consequences. Journal of workplace behavioral health, 21(2), 89-97.

8. Duffy, M.K., Ganster, D.C., \& Pagon, M. (2002). Social undermining in the workplace. Academy of management Journal, 45(2), 331-351.

9. Ferris, D.L., Brown, D.J., Berry, J.W., \& Lian, H. (2008). The development and validation of the Workplace Ostracism Scale. Journal of Applied Psychology, 93(6), 1348.

10. Ferris, G.R., Treadway, D.C., Brouer, R.L., \& Munyon, T.P. (2012). Political skill in the organizational sciences. Politics in organizations: Theory and research considerations, 487-528.

11. Fox, S., \& Stallworth, L.E. (2005). Racial/ethnic bullying: Exploring links between bullying and racism in the US workplace. Journal of vocational behavior, 66(3), 438-456.

12. Heaphy, E.D., \& Dutton, J.E. (2008). Positive social interactions and the human body at work: Linking organizations and physiology. Academy of Management Review, 33(1), 137-162.

13. Hitlan, R.T., Cliffton, R.J., \& DeSoto, M.C. (2006). Perceived exclusion in the workplace: The moderating effects of gender on work-related attitudes and psychological health. North American Journal of Psychology, 8(2), 217-236.

14. Hobfoll, S.E. (1989). Conservation of resources: A new attempt at conceptualizing stress. American psychologist, 44(3), 513.

15. Hobfoll, S.E., \& Shirom, A. (2001). Conservation of resource theory.

16. Hobfoll, S.E. (2002). Social and psychological resources and adaptation. Review of general psychology, 6(4), 307-324.

17. Hobfoll, S.E. (2011). Conservation of resource caravans and engaged settings. Journal of occupational and organizational psychology, 84(1), 116-122.

18. Hobfoll, S.E., Halbesleben, J., Neveu, J.P., \& Westman, M. (2018). Conservation of resources in the organizational context: The reality of resources and their consequences. Annual Review of Organizational Psychology and Organizational Behavior, 5, 103-128.

19. Huertas-Valdivia, I., Llorens-Montes, F.J., \& Ruiz-Moreno, A. (2018). Achieving engagement among hospitality employees: A serial mediation model. International Journal of Contemporary Hospitality Management.

20. Kaya, C. (2017). Workplace ostracism and work engagement.

21. Kurzban, R., \& Leary, M.R. (2001). Evolutionary origins of stigmatization: The functions of social exclusion. Psychological bulletin, 127(2), 187.

22. Leung, A.S., Wu, L.Z., Chen, Y.Y., \& Young, M.N. (2011). The impact of workplace ostracism in service organizations. International Journal of Hospitality Management, 30(4), 836-844.

23. Liden, R.C., \& Mitchell, T.R. (1988). Ingratiatory behaviors in organizational settings. Academy of management review, 13(4), 572-587.

24. MacDonald, G., \& Leary, M.R. (2005). Roles of Social Pain and Defense Mechanisms in Response to Social Exclusion: Reply to Panksepp (2005) and Corr (2005).

25. McCarthy, J.M., Trougakos, J.P., \& Cheng, B.H. (2016). Are anxious workers less productive workers? It depends on the quality of social exchange. Journal of Applied Psychology, 101(2), 279.

26. O'Reilly, J., \& Robinson, S.L. (2009). Ostracism at work: The impact of ostracism on thwarted belongingness and work contributions. In annual meeting of the Academy of Management, Chicago, IL. 
27. Park, J.H., \& Ono, M. (2017). Effects of workplace bullying on work engagement and health: The mediating role of job insecurity. The International Journal of Human Resource Management, 28(22), 3202-3225.

28. Price, J.L. (2001). Reflections on the determinants of voluntary turnover. International Journal of manpower.

29. Renn, R., Allen, D., \& Huning, T. (2013). The relationship of social exclusion at work with selfdefeating behavior and turnover. The Journal of social psychology, 153(2), 229-249.

30. Schmitz, C., \& Ganesan, S. (2014). Managing customer and organizational complexity in sales organizations. Journal of Marketing, 78(6), 59-77.

31. Seibert, S.E., Kraimer, M.L., \& Crant, J. M. (2001). What do proactive people do? A longitudinal model linking proactive personality and career success. Personnel psychology, 54(4), 845-874.

32. Shkoler, O., \& Kimura, T. (2020). How Does Work Motivation Impact Employees' Investment at Work and Their Job Engagement? A Moderated-Moderation Perspective Through an International Lens. Frontiers in Psychology, 11, 38.

33. Sommer, K.L., \& Baumeister, R.F. (2002). Self-evaluation, persistence, and performance following implicit rejection: The role of trait self-esteem. Personality and Social Psychology Bulletin, 28(7), 926938.

34. Tajfel, H. (1978). Social categorization, social identity and social comparison. Differentiation between social group, 61-76.

35. Twenge, J.M., Baumeister, R.F., DeWall, C.N., Ciarocco, N.J., \& Bartels, J.M. (2007). Social exclusion decreases prosocial behavior. Journal of personality and social psychology, 92(1), 56.

36. Warburton, W.A., Williams, K.D., \& Cairns, D.R. (2006). When ostracism leads to aggression: The moderating effects of control deprivation. Journal of Experimental Social Psychology, 42(2), 213-220.

37. Williams, K.D., \& Zadro, L. (2001). Ostracism: On being ignored, excluded, and rejected.

38. Williams, K.D. (2007). Ostracism: The kiss of social death. Social and Personality Psychology Compass, 1(1), 236-247.

39. Wu, L.Z., Yim, F.H.K., Kwan, H.K., \& Zhang, X. (2012). Coping with workplace ostracism: The roles of ingratiation and political skill in employee psychological distress. Journal of Management Studies, 49(1), 178-199.

40. Zadro, L., Williams, K.D., \& Richardson, R. (2004). How low can you go? Ostracism by a computer is sufficient to lower self-reported levels of belonging, control, self-esteem, and meaningful existence. Journal of Experimental Social Psychology, 40(4), 560-567. 